\title{
Papers
}

\section{Cost utility analysis of sildenafil compared with papaverine-phentolamine injections}

\author{
Elly A Stolk, Jan J V Busschbach, Max Caffa, Eric J H Meuleman, Frans F H Rutten
}

\begin{abstract}
Objective To compare the cost effectiveness of sildenafil and papaverine-phentolamine injections for treating erectile dysfunction.

Design Cost utility analysis comparing treatment with sildenafil (allowing a switch to injection therapy) and treatment with papaverine-phentolamine (no switch allowed). Costs and effects were estimated from the societal perspective. Using time trade-off, a sample of the general public $(n=169)$ valued health states relating to erectile dysfunction. These values were used to estimated health related quality of life by converting the clinical outcomes of a trial into quality adjusted life years (QALYs).

Participants 169 residents of Rotterdam. Main outcome measures Cost per quality adjusted life year.

Results Participants thought that erectile dysfunction limits quality of life considerably: the mean utility gain attributable to sildenafil is 0.11 . Overall, treatment with sildenafil gained more QALYs, but the total costs were higher. The incremental cost effectiveness ratio for the introduction of sildenafil was $£ 3639$ in the first year and fell in following years. Doubling the frequency of use of sildenafil almost doubled the cost per additional QALY.
\end{abstract}

Conclusions Treatment with sildenafil is cost effective. When considering funding sildenafil, healthcare systems should take into account that the frequency of use affects cost effectiveness.

\section{Introduction}

The registration of sildenafil has initiated debate about the socioeconomic aspects of this treatment for erectile dysfunction. Generally, governments are concerned about the affordability of sildenafil. ${ }^{1}$ It is not known whether sildenafil is cost effective. Although the clinical effects of sildenafil have been proved, uncertainty remains about the value of sildenafil to both patients and society.

We performed an economic evaluation of sildenafil according to the usual recommendations. ${ }^{2}$ We used cost utility analysis, a form of cost effectiveness analysis in which clinical outcomes are converted into quality adjusted life years (QALYs) gained. Both costs and effects were measured from the societal perspective. This means that treatment outcomes were valued by the general public and that all costs were consideredthat is, medical costs, costs of patients, and costs in other sectors of society. Costs and effects were analysed over five years.

\section{Participants and methods}

We compared the costs of treatment with sildenafil with that of conventional treatment. Before the introduction of sildenafil, injection therapy was the treatment of choice for erectile dysfunction. ${ }^{1}$ Many patients, however, were unwilling to receive injection therapy and accordingly did not seek treatment. We therefore assumed that injection therapy was accepted by $10 \%$ of patients (Pfizer, Netherlands, personal communication, 1998, based on market research). The vasoactive substance was papaverine-phentolamine and not alprostadil, which is more commonly used, because papaverine-phentolamine is less expensive and equally effective. Papaverine-phentolamine injections are reimbursed in the Netherlands, but no decision has yet been taken about reimbursement for sildenafil.

We estimated utility values for different states of erectile dysfunction. These utilities were applied to the clinical outcomes before and after treatment in a clinical trial of sildenafil by Goldstein et al. ${ }^{3}$ We also estimated the costs of two treatment scenarios for erectile dysfunction and analysed these in a model comprising the probabilities of successful treatment, switching and discontinuation of treatment, and duration of successful treatment. A detailed description of our methods to analyse costs and effects is available. ${ }^{4}$

\section{Clinical effects}

The study by Goldstein et al is the largest dose escalation study reported. ${ }^{3}$ It was placebo controlled and the patient population consisted of men with erectile dysfunction due to various causes. Efficacy was assessed with the international index of erectile function. ${ }^{5}$ This instrument contains questions about the two primary end points of erectile dysfunction treatment as defined by the National Institutes of Health-that is, the ability to penetrate and the ability to maintain an erection sufficient for satisfactory sexual intercourse. ${ }^{6}$ These end points were used in the trial. Both questions have five response levels, so together they categorise the patients into $25(5 \times 5)$ erectile dysfunction states. These erectile dysfunction states were valued in a separate

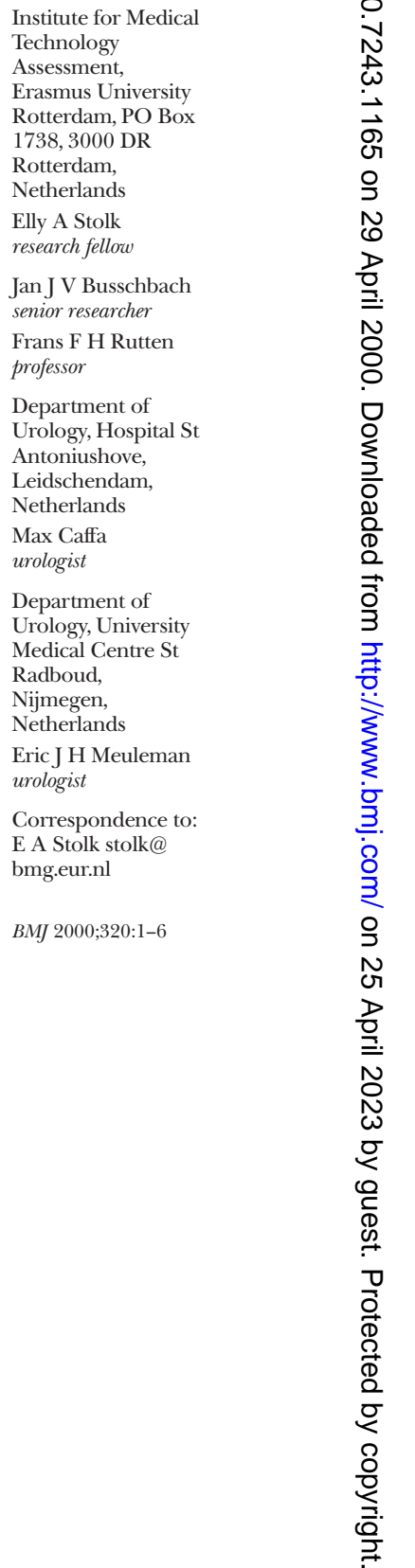


exercise (described below). The elicited utilities were applied to the health states of the patients in the study of Goldstein et al before and after treatment. The difference between the mean utility before and after treatment (controlled for placebo) is the mean gain in utility. Use of disease specific instruments to calculate QALYs is advocated by Brazier and Dixon ${ }^{7}$ and Drummond et al. ${ }^{8}$

Because we used previously reported trial data, we had to consider the limitations of these data for use in economic evaluation. Firstly, the trial was designed on an intention to treat basis, ${ }^{3}$ which meant that patients for whom sildenafil had no or insufficient effect remained in the trial. As we could not discriminate between patients with a sufficient or an insufficient response, we used the mean utility gain in the trial to calculate the utility gain of sildenafil. Consequently, we underestimated the utility gain in daily practice because only the utility gain of the successfully treated patients should be taken into account. Secondly, results of the international index of erectile function were not available for injection therapy, nor were any other data that allowed calculation of QALYs. We conservatively assumed that the utility gain of sildenafil and papaverine-phentolamine injections would be the same. Given the low acceptability of injection therapy, ${ }^{9}{ }^{10}$ this assumption probably overestimates the benefits of injection therapy.

Determining utilities for erectile dysfunction states From a randomly selected sample of 45000 people obtained from the Rotterdam telephone directory we recruited 354 people to participate in the valuation task. They were invited by telephone to attend a session of health state valuation and were offered about $£ 10$ plus travel expenses. In order to avoid selection bias, the invitation was made without referring to erectile dysfunction. Participants were given the opportunity to withdraw from the valuation sessions without financial consequences after they were informed about the subject of the study.

Participants valued 24 erectile dysfunction states on a scale from 0 to 1 using time trade-off. ${ }^{8}$ The 25 th state described normal erectile functioning and was set at a value of 1.0. Time trade-off was measured relative to the life expectancy of the subjects. Before the valuation task, participants gained experience of the time trade-off method using general health states as defined by the EQ-5D questionnaire. ${ }^{11}$

Time trade-off responses were considered invalid if the participant showed a lexicographic response for the EQ-5D states, had too much missing data either on erectile dysfunction or EQ-5D states, or clearly did not understand the task. A lexicographic response mode means that when a respondent is faced with an option he or she will always choose one particular alternative, no matter how favourable the other might be. Subjects had to value the health states "for a person like yourself." This means, for example, that older people gave values from their own perspective, and people without a sexually active partner would take this into account when performing the valuation task. The exception was that women were asked to imagine being a man with erectile dysfunction. Values are independent of the sexual activity of the respondents because the descriptions of erectile function referred to the relative number of successful attempts at intercourse. For example, a respondent might be asked the following: "If during the past four weeks, your condition was such that you were sometimes able to attain an erection, and you were (almost) never able to maintain your erection, how many years would you be willing to trade off to restore your erectile function?" This also implies that erectile function is valued the same in patients with different levels of sexual activity.

Because we had decided to obtain social valuations we asked a sample of the general public to value the clinical outcomes. ${ }^{812}$ The reasoning behind this decision relates to issues of equity and medical ethics. ${ }^{13}$ Some authors, however, claim that healthy people relatively similar to affected patients should value clinical outcomes. ${ }^{14}$ We therefore explored whether erectile dysfunction is valued differently in different subgroups. We used multivariate analysis of variance to determine whether age, sex, the availability of a partner, having children, sexual activity, and sexual satisfaction influenced the values of the general public.

\section{Costs}

All costs are expressed in 1999 British pounds (£1=1.62 euro). We used 1999 data to determine the Dutch cost prices. To determine the medical costs, we estimated resource use-for example, consultations and prescription charges (a lump sum charge to refund pharmacy costs and medicines) and multiplied the quantities by the unit prices. We estimated resource use of sildenafil and papaverine-phentolamine injections on the basis of consensus statements on both treatments. ${ }^{15}$ We refined this estimate by developing a low, baseline, and high cost scenario on the basis of clinical experience in two hospitals (University Medical Centre St Radboud, Nijmegen and Hospital St Antoniushove, Leidschendam). Costs outside the healthcare sector and productivity costs were assumed to be negligible.

The cost of sildenafil was based on observational data from the first quarter that sildenafil was available in the Netherlands. ${ }^{16}$ A general practitioner or urologist determined the effective dose in an academic or peripheral setting. An appropriate share of the costs of supporting departments was reflected in the cost of a visit to a urologist. The physician's costs were calculated on the basis of the estimated duration of an outpatient visit. The analysis included all costs related to the hospital, such as costs of salaries and supplies, costs of supporting departments, and overhead costs.

\section{Cost effectiveness}

We compared two scenarios: treatment with sildenafil and treatment with papaverine-phentolamine (figure). In the sildenafil scenario, we allowed patients to switch to papaverine-phentolamine injections, as these injections may be effective in patients in whom sildenafil has failed. Since sildenafil has already become the treatment of choice, although its cost is not reimbursed in the Netherlands, patients are unlikely to switch from injections to sildenafil. A switch was therefore not allowed in the papaverine-phentolamine scenario.

We compared the sildenafil and papaverinephentolamine scenarios assuming use once a week. The maximum recommended frequency of papaverine-phentolamine injections is once a week, 
but use of sildenafil is not limited for medical reasons. Nevertheless, we believe that the assumption was appropriate as the utility values were elicited independently of the frequency of intercourse. Moreover, the marginal utility gain of increasing intercourse frequency from once to twice a week is unlikely to be as high as the increase between never being able to have intercourse and being able to have intercourse once a week.

The cost effectiveness of the different scenarios was analysed in a model comprising acceptability of treatment, probability of successful treatment, switching or discontinuation of treatment, and the duration of successful treatment. The patient flows in the model were determined on the basis of secondary data-for example, published clinical trials, ${ }^{9-20}$ Dutch observational data, ${ }^{16}$ and clinical experience in the two participating hospitals. We performed an incremental analysis of the costs and effects of sildenafil compared with papaverine-phentolamine. The results are presented as cost per QALY.

The acceptance rate of papaverine-phentolamine treatment could have been influenced by the fact that erectile dysfunction is no longer a taboo subject. In fact, an acceptance rate of $70 \%$ has been suggested as feasible. ${ }^{21}$ We therefore included this variable in a sensitivity analysis. Other variables included in the sensitivity analysis were resource use, values, effectiveness of treatment, and frequency of use. We performed univariate sensitivity analysis to determine which variables have the largest influence on the results. In the multivariate sensitivity analysis we explored to what extent results would change under a (unlikely) worst case scenario.

\section{Results}

\section{Respondents}

A total of 184 subjects (52\%) failed to attend the interview sessions. This was probably because of extremely bad weather at the time of interview, which made it difficult for participants to reach the university. One person withdrew from the study after he was informed about the subject. A sample of 169 subjects valued the erectile dysfunction states; $89 \%$ (150) of the responses were valid. Age ranged from 18 to 80 years (mean age of 45.8 (SD 15.4) years). There were 81 men (54\%) and 69 women, which is close to the sex distribution in the general population.

\section{Effects}

In Goldstein et al's study the international index of erectile function among men receiving sildenafil rose from 2.0 at baseline to 3.9 at end of treatment for ability to penetrate (placebo group 2.1 to 2.3 ) and from 1.5 to 3.6 for satisfactory sexual intercourse (placebo

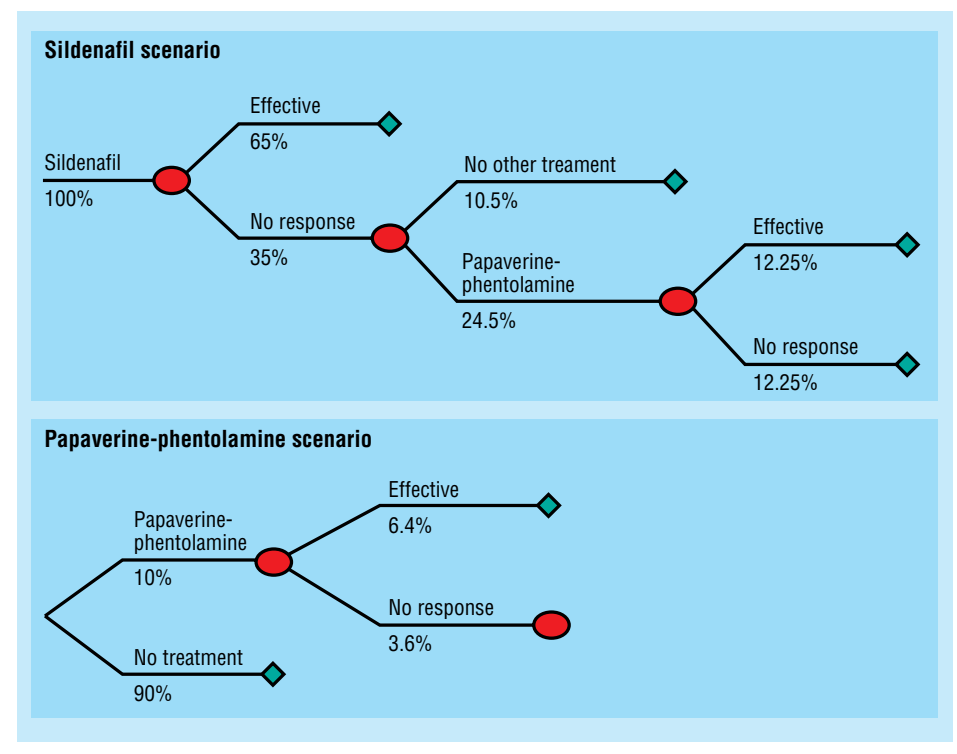

Patient flow for scenarios of treatment of erectile dysfunction with sildenafil or papaverine-phentolamine injections

group 1.6 to 1.8$){ }^{3}$ Table 1 gives the mean utilities that were elicited for the 24 erectile dysfunction states described by these two questions. The utilities ranged from 0.74 to 0.94 . When these values are combined with trial data, the mean utility increased from 0.807 at baseline to 0.915 at end of treatment for men receiving sildenafil and from 0.819 to 0.821 for men receiving placebo. Therefore, the mean utility gain attributable to sildenafil is 0.11 .

We analysed whether the values of the general public were influenced by age, sex, availability of a partner, having children, sexual activity, and sexual satisfaction. The only relation we found was that participants with children considered erectile dysfunction less of a problem than subjects without children. Since there were no differences between the values of men and women, we used averaged values in the QALY analysis. More extensive description of this analysis is available. $^{22}$

\section{Costs}

Tables 2 and 3 show the resource use and the costs attributable to treatment of erectile dysfunction with sildenafil or papaverine-phentolamine injections. Papaverine-phentolamine is cheaper per dose, but it has to be prescribed by an urologist and therefore has higher initial costs ( $£ 484$ versus $£ 407$ for sildenafil). Sildenafil has higher running costs: yearly treatment costs are $£ 254$ versus $£ 233$ for papaverinephentolamine. The higher initial costs of papaverinephentolamine are recovered after seven years.

Table 1 Mean (SD) utility values assigned by general public for erectile dysfunction $(n=150)$

\begin{tabular}{llllll}
$\begin{array}{l}\text { Ability to maintain an } \\
\text { erection }\end{array}$ & Never & Few times & Sometimes & Most times & Always \\
\cline { 2 - 6 } Never & $0.74(0.18)$ & $0.79(0.17)$ & $0.82(0.17)$ & $0.82(0.15)$ & $0.84(0.17)$ \\
\hline Few times & $0.77(0.18)$ & $0.83(0.16)$ & $0.85(0.16)$ & $0.86(0.15)$ & $0.88(0.16)$ \\
\hline Sometimes & $0.79(0.16)$ & $0.85(0.14)$ & $0.87(0.14)$ & $0.90(0.13)$ & $0.91(0.13)$ \\
\hline Most times & $0.81(0.17)$ & $0.86(0.15)$ & $0.88(0.14)$ & $0.94(0.12)$ & $0.93(0.13)$ \\
\hline Always & $0.82(0.17)$ & $0.87(0.15)$ & $0.91(0.13)$ & $0.94(0.11)$ & 1.00
\end{tabular}


Table 2 Volumes of resource use for sildenafil and injection treatment*

\begin{tabular}{|c|c|c|}
\hline Resource & Sildenafil & Injection \\
\hline \multicolumn{3}{|l|}{ General model: } \\
\hline Acceptability of treatment (\%) & 100 & 10 \\
\hline$\%$ treated by general practitioner & 80 & 10 \\
\hline$\%$ treated by urologist & 20 & 90 \\
\hline No of pills or injections a week & 1 & 1 \\
\hline \multicolumn{3}{|l|}{ Establishing effective dose: } \\
\hline No of visits & 3.8 & 3.7 \\
\hline Mean duration of visits (min) & 8.5 & 10.3 \\
\hline No of prescriptions ${ }^{16}$ & 2.5 & 2.3 \\
\hline$\%$ discontinuing treatment ${ }^{9} 1017-20$ & 35 & 36 \\
\hline$\%$ switching because of effectiveness & 50 & 0 \\
\hline \multicolumn{3}{|l|}{ Remaining part of first year: } \\
\hline No of visits & 2.0 & 2.0 \\
\hline Mean duration of visits (min) & 7.5 & 7.5 \\
\hline No of prescriptions ${ }^{16}$ & 7.8 & 4.3 \\
\hline$\%$ discontinuing treatment $(\%)$ & 10 & 14 \\
\hline \multicolumn{3}{|l|}{ Each following year: } \\
\hline No of visits & 1.5 & 1.5 \\
\hline Mean duration of visits (min) & 7.5 & 7.5 \\
\hline No of prescriptions ${ }^{16}$ & 9.5 & 5.2 \\
\hline$\%$ discontinuing treatment & 5 & 5 \\
\hline \multicolumn{3}{|c|}{$\begin{array}{l}\text { *As far as possible estimations are supported by scientific publications. When } \\
\text { no scientific publications were available, estimations were derived from the } \\
\text { opinion of clinical experts in the two participating hospitals. Figures of } \\
\text { acceptability of treatment and proportion of patients treated by general } \\
\text { practitioner or urologist were provided by Pfizer (based on market research, } \\
\text { 1998). }\end{array}$} \\
\hline
\end{tabular}

Table 3 Unit costs $(£)$ of sildenafil and injection treatment

\begin{tabular}{|c|c|}
\hline Units of resource use & $\begin{array}{l}\text { Cost price } \\
\text { (without value } \\
\text { added tax) }\end{array}$ \\
\hline Sildenafil tablet ${ }^{16}$ & $4.33^{\star}$ \\
\hline Papaverine-phentolamine injection & 3.55 \\
\hline Visit to general practitioner (<20 min) & 10.32 \\
\hline $\begin{array}{l}\text { Visit to urologist (weighted mean, university/ peripheral } \\
\text { hospitals) }\end{array}$ & $\begin{array}{l}1.29 / \mathrm{min} \\
\text { plus } 16.80\end{array}$ \\
\hline Prescription rule (charge to refund pharmacy costs) & 3.14 \\
\hline
\end{tabular}

\section{Cost effectiveness}

Overall, sildenafil creates more benefits and more costs because more patients are treated (figure). Therefore, the main issue is whether the additional effects of sildenafil are worth the additional costs. This question is addressed in the incremental analysis shown in table 4 . The incremental cost utility ratio of sildenafil compared with papaverine-phentolamine is $£ 3639$ per QALY in the first year, decreasing to $£ 2630$ per QALY after five years.

\section{Sensitivity analysis}

The frequency of use influences the outcomes considerably. Doubling the frequency of use of sildenafil increases the cost per additional QALY by $45 \%$ in the first year and $85 \%$ in each following year. The initial costs are relatively high because the costs of non-responders are added to the costs of responders. Hence, the effect of the frequency of use on the cost per additional QALY is moderated in the first year. In the long term, however, the main cost driver with sildenafil is the drug.

Assuming a lower utility gain (0.08) than observed in the valuation study, resulted in a $37.5 \%$ increase in cost per additional QALY ${ }^{4}$ Effectiveness and acceptability also influenced the results significantly. The cost per additional QALY increased 38\% with a lower effectiveness of sildenafil (50\%), but decreased (1\%) in each following year. Changes in acceptability had an opposite effect: when acceptability of papaverinephentolamine injections is increased to $70 \%$, the incremental cost utility ratio is $25 \%$ lower in the first year, but $10 \%$ higher from the second year onwards. Uncertainty about resource use did not influence the outcomes significantly; in the analysis of different cost scenarios (based on the number of visits and duration of visits), the high cost scenario increased the costs per additional QALY by only $8 \%$.

When the uncertainty of all variables is combined into a worst case model (low utility gain and effectiveness and high costs, dropout, and acceptability), the incremental cost utility ratio is $£ 9343$ per QALY in the first year( $156 \%$ increase), and $£ 4691$ in each following year( $101 \%$ increase).

\section{Discussion}

The mean incremental cost utility ratio of sildenafil compared with papaverine-phentolamine was £3639 per QALY in the first year and improved in the following years. This cost utility ratio is generally favourable, as suggested acceptable thresholds of cost utility vary between $£ 8000$ and $£ 25000 .^{23}$ Moreover, many interventions with less favourable cost utility ratios are currently being funded, such as breast cancer screening ( 5780 per QALY) and kidney transplantation ( $£ 4710$ per QALY). ${ }^{25}$ Uncertainty in the data did not hamper interpretation of the results: even in the worst case scenario, the incremental cost utility ratio of $£ 9343$ could be considered favourable. Our analysis therefore suggests that the clinical effect is derived at reasonable costs.

Table 4 Costs and effects of treatment with sildenafil and papaverine-phentolamine injection and difference between two treatments

\begin{tabular}{|c|c|c|c|c|c|}
\hline \multirow[b]{2}{*}{ Year } & \multicolumn{2}{|c|}{ Successfully treated patients (\%) } & \multirow{2}{*}{$\begin{array}{l}\text { Incremental cumulative } \\
\text { effects (QALY) }\end{array}$} & \multirow{2}{*}{$\begin{array}{l}\text { Incremental cumulative } \\
\text { costs }(£)\end{array}$} & \multirow{2}{*}{$\begin{array}{l}\text { Incremental cost utility } \\
\text { ratio (£/QALY) }\end{array}$} \\
\hline & Sildenafil & Injection & & & \\
\hline 1 & 77.25 & 6.40 & 7.79 & 28368 & 3639 \\
\hline 2 & 69.53 & 5.50 & 14.84 & 44773 & 3017 \\
\hline 3 & 66.05 & 5.23 & 21.53 & 60356 & 2803 \\
\hline 4 & 62.75 & 4.97 & 27.88 & 75161 & 2695 \\
\hline 5 & 59.61 & 4.72 & 33.92 & 89226 & 2630 \\
\hline$\infty^{*}$ & & & & & 2329 \\
\hline
\end{tabular}




\section{What is already known on this topic}

Clinical research suggests that sildenafil is an effective treatment for erectile dysfunction

Economic appraisal of sildenafil is needed given the prevalence of the disorder and controversy regarding funding of treatment

\section{What this study adds}

Erectile dysfunction is generally perceived as a disease that limits quality of life considerably

The clinical effect of sildenafil is derived at reasonable costs

Health service funding of sildenafil should be considered

\section{Validity of assumptions}

We made several assumptions that could be viewed as unfavourable to sildenafil. For instance, we underestimated the effects by not including partner satisfaction and we assumed the effects of oral and injection treatment to be equal. Furthermore, we used a relatively low rate of drop out for injection therapy, which results in a more favourable cost effectiveness ratio for injection therapy. ${ }^{9-20}$ Although such assumptions might introduce bias, the interpretation of the results is not greatly affected because the assumptions in the economic appraisal of sildenafil were conservative.

The utility values we elicited for erectile dysfunction did not take into account possible comorbidity. As in most cases total disutility is less than the sum of parts, ${ }^{26}$ we might have overestimated the effect. However, the sensitivity analysis showed that sildenafil remained cost effective with lower utility gains.

The subjective nature of the value of erectile functioning again raises issues about whose values should be used in economic appraisal of health care: the values of the general public or those of people at risk (in our case ageing men). However, we found that the utility values for sexual functioning were independent of background variables such as age, sex, and sexual activity. Therefore, neither the limitations in the representativeness of our sample, nor our choice to elicit values from the general public has influenced the results.

\section{Implications}

These findings should be interpreted in the light of the discussion about the affordability and value of sildenafil to society. Firstly, we have shown that erectile dysfunction limits quality of life considerably, in the eyes of the general public. Furthermore, our study shows that sildenafil is cost effective, and its reimbursement should therefore be considered. However, as frequency of use greatly affects cost, such reimbursement should not be unconditional.

We thank L Damen and P Rabsztyn, who provided us with details about the treatment scenarios. Blauw Call Centre Rotterdam recruited the general population subjects, $L$ van der Hell assisted with the interviews, and Rosalind Rabin edited the English.
Contributors: FFHR initiated the research, discussed core ideas, commented on drafts of the manuscript, and is guarantor of this study. JJVB designed the study, particularly the collection of quality of life data. He also contributed to data analysis and interpretation and writing the paper. EAS carried out the data collection, performed the data analysis, and produced the main drafts of the paper. MC and EJHM developed the treatment scenarios, contributed to the data collection and interpretation, and commented on drafts of the manuscript. All authors approved the final version of the article.

Funding: This research project was undertaken in support of the economic report requested by the Dutch Health Authorities to inform their decisions regarding the reimbursement of sildenafil. The research was supported by an unrestricted grant from Pfizer BV in the Netherlands.

Competing interests: All authors have received reimbursements from Pfizer for attending symposia or fees for consultancy and speaking or both.

1 Dinsmore W, Evans C. ABC of sexual health: erectile dysfunction. $B M$ 1999;318:387-90.

2 Gold MR, Siegel JE, Russell LB, Weinstein MC. Cost-effectiveness in health and medicine. New York: Oxford University Press, 1996.

3 Goldstein I, Lue TF, Padma-Nathan H, Rosen RC, Steers WD, Wicke WA, for the Sildenafil Study Group. Oral sildenafil in the treatment of erectile dysfunction. N Engl J Med 1998;338:1397-404.

4 Stolk EA, Busschbach JJV, Caffa M, Meuleman EJH, Rutten FFH. The costutility of Viagra in the Netherlands. Rotterdam: Institute for Medical Technology Assessment, 1999. (No 99.49.)

5 Rosen RC, Riley A, Wagner G, Osterloh IA, Kirkpatrick J, Mishra A. The international index of erectile function (IIEF): a multidimensional scale for assessment of erectile dysfunction. Urology 1997;49:822-30.

6 National Institutes of Health Consensus Conference. NIH Consensus Development Panel on Impotence. JAMA 1993;270:83-90.

7 Brazier J, Dixon S. The use of condition specific outcome measures in economical appraisal. Health Econ 1995:255-64.

8 Drummond MF, O'Brien B, Stoddart GI, Torrance GW. Methods for the economic evaluation of health care programmes. Oxford: Oxford University Press, 1997

9 Mulhall JP, Jahoda AE, Cairney M, Goldstein B, Leitzes R, Woods J, et al. The causes of patient dropout from penile self-injection therapy for impotence. J Urol 1999;162:1291-4.

10 Althof S, Turner L, Levine S, Risen C, Kursch E, Bodner D, et al. Why do so many people drop out from auto-injection therapy for impotence? $J$ Sex Marital Therapy 1989;15:121-9.

11 Brooks R. EuroQol: the current state of play. Health Policy 1996;37:53-72

12 Gold MR, Patrick DL, Torrance GW, Fryback DG, Hadorn DC, Kamlet MS, et al. Identifying and valuing outcomes. In: Gold M, Siegle J, Russel L, Weinstein M, ed. Cost-effectiveness in health and medicine. New York: Oxford University Press, 1996:82-134.

13 Williams A. Economics, QALYs and medical ethics. A health economist's perspective. York: Centre for Health Economics, York Health Economics Consortium, NHS Centre for Reviews and Dissemination, 1994. (Discussion paper 121.)

14 Hadorn DC. The role of public values in setting health care priorities. Soc Sci Med 1991;32:773.

15 Diagnosis and treatment of erectile dysfunction: step by step. Round table conference. Rotterdam: Medicom Excel, 1998 (In Dutch.)

16 Foundation of Pharmaceutical Statistics. Pharmaceutical statistics. The potency of Viagra in the Netherlands. Weekly Pharmaceutics 1999;134(6).

17 Meuleman EJH, Van Berkel JTH, Rabsztyn P, Damen L. Sildenafil (Viagra) in the treatment of erectile dysfunction. Ned Tijdschr Geneesh 1998;142:2337-41. (In Dutch.)

18 Jarow JP, Burnett AL, Geringer AM. Clinical efficacy of sildenafil citrate based on etiology and response to prior treatment. J Urol 1999;162:722.

19 Jackson SE, Lue TF. Erectile dysfunction: Therapy health outcomes. Urology 1998;51:874-82.

20 Korenman SG. New insights into erectile dysfunction: a practical approach. Am J Med 1998;105:135-44.

21 Lycklama à Nijeholt AAB. The erection pill. Ned Tijdschr Geneesk 1998;142:2332-3. (In Dutch.)

22 Stolk EA, Busschbach JJV. Differences in the values given by the general public and patients to health states of erectile dysfunction. In: Stolk EA, Busschbach JJV, eds. The cost-utility of Viagra in the Netherlands. Rotterdam: for Medical Technology Assessment, Erasmus University, 1999:65-82 appendix B.

23 Laupacis A, Feeny D, Detsky AS, Tugwell PX. How attractive does a new technology have to be to warrant adoption and utilization? Tentative guidelines for using clinical and economic evaluations. Can Med Ass J 1992;146:473-81.

24 Goldman L, Gordon DJ, Rifkind BM, Hulley SB, Detsky AS, Goodman DS, et al. Cost and health implications of cholesterol lowering. Circulation 1992;85:1960-8

25 Maynard AK. Developing the health care market. Econ J 1991;101:127786.

26 Furlong W, Feeny D, Torrance GW, Goldsmith CH, DePauw S, Zhu Z, et al. Multiplicative multiattribute utility function for the health utilities index mark (HUI 3) system: a technical report. Hamilton, Ontario: McMaster University Centre for Health Economics and Policy Analysis, 1998:5-6. (Working paper 98-11.)

(Accepted 21 January 2000) 